\title{
El movimiento católico en España: la respuesta de la provincia eclesiástica de Valladolid a la encuesta Vico (1908)
}

\author{
F. Montero Garcia *
}

A menudo se ha hecho separadamente la historia del catolicismo social y del catolicismo político, y al hacerlo, se ha insistido demasiado, como en otros temas, en la peculiaridad del catolicismo español. La encuesta sobre la posibilidad de aplicar a España el modelo italiano de acción católica, una de cuyas respuestas más representativas presentamos, permite, por un lado, ensayar directamente la perspectiva comparativa, concretamente con el Movimiento católico italiano (sobre el que disponemos de abundante bibliografia), y por otro lado, la encuesta nos invita directamente a considerar la globalidad del Movimiento católico: acción propagandistica, obras escolares, obras benéfico-sociales, acción política. Las investigaciones sobre el catolicismo español deberian insistir más en esta perspectiva global y comparativa '.

\section{LOS ANTECEDENTES DEL MOVIMIENTO CATÓLICO EN ESPAÑA}

La iniciativa concreta tomada por el nuncio Vico, con el impulso principal del Vaticano, y el apoyo de algunos obispos españoles, hay que si-

* Departamento Historia Contemporánea UNED.

Esta breve introducción al documento presentado, la respuesta de la Provincia eclesiástica de Valladolid a la encuesta promovida por el nuncio Víco, remite a una comunicación presentada por el autor a un reciente coloquio sobre "Eglise, Etat et societé. Espagne, France, Italie: epoque contemporaine" celebrado en Niza, febrero 1992 titulada "La organización de la acción Católica en España. La encuesta Vico. Encuesta sobre la posible aplicación a España de las normas italianas dadas por Pio X". En vias de publicación en las Actas del Coloquio. 
tuarla en un doble contexto eclesial, español e italiano. De un lado el modelo italiano de la Acción Católica, surgido de la crisis de L'opera dei Congressi ${ }^{2}$, que es precisamente el modelo organizativo que se va a proponer a los católicos españoles. De otro lado, la fuerte división politica de los católicos españoles que habia frustrado los sucesivos intentos de la Santa Sede, especialmente desde los primeros Congresos Católicos (1889-1894), de organizar una acción política unitaria, en torno a un programa electoral.

En este sentido, la encuesta promovida por el nuncio, en sucesivas circulares de marzo y junio de 1908, sobre la posibilidad de aplicar al catolicismo español el triple estatuto italiano, enlaza con iniciativas anteriores: la politica de Rampolla en su etapa de nuncio en Madrid, los impulsos a Sancha para la puesta en marcha de los Congresos Católicos, el Programa por la unidad aprobado en el Congreso de Burgos (1899), el acuerdo del Congreso de Santiago (1902), la carta de Pío $X$ «Inter Catholicos Hispaniae» (1906) ${ }^{3}$.

Entre 1902, último Congreso nacional católico, en Santiago, y la encuesta de 1908, la Junta Central de A.C. y el Consejo Nacional de Corporaciones Católico-obreras, intentaron impulsar respectivamente la creación de consejos diocesanos de A.C. (en 1908 según la memoria de la Junta Central habia 27 constituidos), y la celebración de asambleas regionales de corporaciones católico-obreras, aunque siempre con una gran escasez de medios.

Paralelamente la Santa Sede trataba de suscitar la acción coordinada de los obispos. En 1908 la iniciativa vaticana tomó una forma muy concreta. Se trataba de consultar directamente a los obispos, y a algunos

\footnotetext{
${ }^{2}$ La bibliografía italiana sobre el Movimiento Católico y la Acción Católica es muy abundante. Entre otros vid. RosA, G. de, /l Movimento Catolico in Italia, 1966; varias voces del Dizionario Storico del Movimento catolico in Italia, 1860-1980.

${ }^{3}$ Para todas estas referencias a los antecedentes del Movimiento católico en España, vid. Robles, C., Insurrección o legalidad, CSIC, y sus artículos, "Frente a la supremacia del Estado. La Santa Sede y los católicos en la crisis de la Restauración, 1898-1912"; "Antologica Annua", 34 (1987) y 36 (1989); Montero, F., El primer catolicismo social y la Rerum Novarum en España, CSIC, Madrid 1983; Andres Gallego, J., Pensamiento y acción social de la Iglesia. Madrid, ed. Espasa, 1984; y La politica religiosa...

La historiografia española ha estudiado demasiado separadamente el catolicismo social del catolicismo político. Sólo recienteınente ha utilizado el concepto historiográfico "Movimiento católico". Un ejemplo brillante la reciente tesis doctoral de FulLANA, Pere, "El Moviment catolic a Mallorca" Un. Baleares 1991. También varios trabajos de ComEs, V., sobre el Movimiento Católico en Valencia. Una definición contemporánea del concepto en el "Informe sobre la Acción católica en el orden público» elaborado por la Nunciatura de Madrid en 1896, tras la primera serie de Congresos Católicos, publicado por CARCEL ORTı, V., en León XIII y los católicos españoles. Pamplona, ed. Eunsa, 1988.
} 
religiosos y seglares cualificados sobre la posibilidad de aplicar a España el modelo italiano, que preveia la organización separada, aunque coordinada, de la actividad propagandistica (Unión Popular), de la acción social (Unión económico-social), y de la acción política (la Unión politicoelectoral). De las tres uniones propuestas indudablemente la más dificil de poner en marcha era la última. Para la formación de las dos primeras habia ya experiencias de las que partir, e incluso algunas plataformas organizativas (consejos diocesanos, Asambleas regionales, Junta Central de A.C., Consejo Nacional de corporaciones católico-obreras) aunque no totalmente desarrolladas e implantadas. Pero respecto de la unión politico-electoral todos los proyectos anteriores habian fracasado. No debe extrañar que la encuesta, tanto la pregunta como las respuestas, se centrara fundamentalmente en esta cuestión.

\section{LA ENCUESTA DE $1908^{4}$}

La encuesta se desarrolló en dos fases principales:

- En una primera circular del nuncio a los obispos españoles, el 18 de marzo de 1908, se comunica el deseo del Papa de pulsar la opinión de aquellos sobre la oportunidad de las directrices dadas al Movimiento católico italiano antes de responder a la demanda de los propios obispos españoles, reunidos en Palencia con ocasión de la asamblea regional de corporaciones católico obrera, sobre la organización de la "Acción Popular católica Española". La pregunta fundamental era ¿cómo conseguir la unión de los católicos en la acción católica y en la acción política?

La respuesta de los obispos a esta primera circular, entre marzo y junio de 1908, parece que no fue completa ni demasiado concreta salvo excepciones. Varios piden los estatutos italianos, y una mayor concreción de la propuesta vaticana para poder contestarla.

- A esta demanda de concreción responde el envio por parte del nuncio de una segunda circular, el 30 de junio, con una propuesta

\footnotetext{
${ }^{4}$ Para todo el proceso de la encuesta vid. Archivo Secreto Vaticano (ASV), Nunciatura Madrid, 690, fasc. 1, 2, 3, 4. La iniciativa de la encuesta y la propuesta de inspirar el modelo español en el modelo italiano parece enteramente vaticana, con especial intervención del Secretario de Estado Merry del Val; pero se plantea como respuesta a una petición concreta de los obispos españoles.
} 
concreta y desarrollada, directamente inspirada en la A.C. italiana. Se adjuntaban un folleto impreso sobre bases para la organización de la A.C. española y de las tres "Uniones", siguiendo los estatutos italianos, y unas "reglas prácticas" sobre el comportamiento politico de los católicos. Además se incluia en la encuesta un proyecto de «Agremiación sacerdotal nacional» que había remitido el de Santiago a partir de un modelo del P. Vicent ${ }^{5}$.

Las respuestas episcopales a esta segunda circular se suceden entre julio y octubre. Ahora si, la respuesta era bastante completa, y elaborada. Hay incluso algunas respuestas colectivas como la de la provincia eclesiástica de Valladolid, reunida en Salamanca, cuyo documento presentamos aquí. En todo caso las respuestas, agrupadas por provincias, fueron remitidas desde el respectivo metropolitano. Además de la respuesta de los obispos emitieron también su opinión algunos religiosos especialmente vinculados a la acción social católica, como el P. Palau, fundador de Acción Social Popular, o el P. Vicent, la Junta Central de A.C. que remitió un extenso folleto con el resumen de la actividad desplegada desde los primeros Congresos católicos, y a título personal, algunos seglares como el Marqués de Comillas, Rafael Rodriguez de Cepeda, y el senador Conde de Torres Cabrera.

Con todas estas respuestas, el nuncio elaboró un extenso resumen de las opiniones emitidas y un balance final de la posición de los católicos en relación con la propuesta vaticana, que constituye la base del informe que remite al Secretario de Estado, Merry del Val, el 16 de mayo de 1909, casi un año después de la segunda circular. En la respuesta de Merry se asumian por parte de la Santa Sede las conclusiones de la encuesta: no creía conveniente la aplicación a España de las normas italianas; para guardar la unidad el Papa nombraria un nuevo primado ${ }^{6}$.

Una tercera circular del nuncio a los obispos españoles, el 15 de julio de 1909, significa el final de la encuesta iniciada en marzo de 1908. En ella, tras agradecer en nombre del Papa la unanimidad

${ }^{5}$ El 11 de junio en la respuesta a la $1 .^{a}$ circular, el arzobispo de Santiago envió unos "Estatutos de la Agremiación sacerdotal nacional" según modelo del P. Vicent, con el deseo de que se aprueben para toda España, ASV, N. Madrid, 690, 2, ff. 216-217.

${ }^{6}$ Resumen del nuncio "L'Azione cattolica nella Spagna" ASV, N, Madrid, 690, 2, ff 208218. Informe del nuncio de 16-V.1909 y respuesta de Merry el 25-VI en ASV, N. Madrid 690 fasc. $4,98-104$. 
de la respuesta episcopal, el nuncio sacaba conclusiones y marcaba directrices:

"no cree llegado el momento de resolver sobre la aplicación de los estatutos italianos a este pais". (...) "Que los obispos trabajen a nivel diocesano en impulsar la acción social sobre la base de lo ya existente". (...) En cuanto a la unión electoral, que se aplique la carta cInter catholicos Hispaniae".

Las respuestas episcopales a la tercera circular, en general meros acuses de recibo, se suceden entre julio y septiembre de 1909. La mayoria comparten el criterio del nuncio de separar las distintas posibilidades de la unión por la acción politica (muy escasas), y para la acción social (habia que potenciarla) ?

De acuerdo, con las instrucciones de Merry, y la tercera circular del nuncio a los obispos, el nuevo primado deberia hacer algún gesto para impulsar la unidad. Puesto que la encuesta había dejado claro la imposibilidad de aplicar a España el modelo italiano A.C., y, sobre todo, la de llegar a la unión político electoral. Entre septiembre y octubre el nuncio mantiene correspondencia, en paralelo, con el de Valencia Guisasola y con el primado Aguirre para la preparación de las normas que finalmente se publicarán en enero de $1910^{8}$.

\section{LA PROPUESTA DEL VATICANO}

En el documento-base de la encuesta, Normas y Bases para la Acción Católica Española (Madrid 1908) ${ }^{9}$, que concretaba el proyecto para la aplicación a España del modelo de A.C. italiana, (el triple estatuto), remitido junto con la segunda circular a todos los obispos españoles, se presentaban sucesivamente: las Normas fundamentales para la acción católica española junto al modelo vigente en España de "Consejo diocesano de las corporaciones o asociaciones católica", El Estatuto o Bases de la

Circular sopra l'innoportunita di applicare gli statuti italiani in Spagna, Uniones dei cattolici nell'azione elettorale», ASV, N.M., 690 (3), f. 188.

${ }^{8}$ Vid. ASV, N. Madrid, 690, fasc, 4.

${ }^{9}$ Todas las referencias y citas de este apartado son del folleto impreso, Normas y Bases para la Acción católica Española. Las bases italiana acomodadas... Madrid 1908, ASV, N. Madrid, 690,2 ,ff. $87-114$. 
"Unión Popular" entre los católicos de España, El Estatuto o Bases de la Unión Económica Social católica española, y finalmente El Estatuto o Bases de la Unión electoral católica española.

El modelo de A.C. a imitar y envidiar era el alemán. Pero la organización tenia que adaptarse a las circunstancias particulares de cada pais. Italia habia encontrado recientemente su modelo. ¿No podrá aplicarse a España este modelo, teniendo en cuenta las semejanzas de la circunstancia española?

En las Normas fundamentales para la A.C.E. destacaba la dirección diocesana, bajo la dependencia directa del obispo respectivo, como la base fundamental de la organización. La norma octava decía taxativamente: "Las Asociaciones católicas que tengan igual o parecida finalidad, podrán unirse en federaciones diocesanas regionales y nacionales, de acuerdo con la propia Dirección diocesana y con el "consentimiento del Ordinario respectivo". Esta autonomía y máxima responsabilidad diocesana será uno de los elementos en el que insistirán la mayoria de los encuestados. Para algunos será un instrumento de resistencia a la organización unitaria y central de la A.C., según el modelo italiano.

La Unión Popular católica, según el modelo italiano aprobado en Florencia en febrero de 1906, era definida como «un centro común de doctrina, propaganda y organización social». La propuesta de «Estatutos 0 Bases de la "Unión Popular» entre los católicos de España» se constituia con tres tipos de obras, correspondientes a esos tres objetivos: obras de estudio, obras de propaganda y obras de organización.

Tanto la Unión Popular como las otras Uniones deberian tener su sede en Madrid, lo que suscitó no pocas reticencias y recelos, especialmente entre los propagandistas ( $P$. Palau fundador de la Acción Social Popular) y obispos catalanes.

El Estatuto o Bases de la Unión Económica social católica española, vendría a integrar y suplir el Consejo Nacional de corporaciones católicoobreras, nacido en Valencia en 1893. La organización de esta Unión partía de las organizaciones diocesanas y regionales preexistentes, que en esos últimos años estaban consolidándose (Asambleas regionales de corporaciones católico-obreras del norte (Palencia), levante (Valencia), sur (Granada). En el consejo directivo se constituirian tantas secciones como tipos de asociaciones pretendian integrarse en la unión: los Círculos Católicos, los Sindicatos obreros, los Sindicatos agrícolas, las Cooperativas, las Cajas rurales ${ }^{10}$.

10 Los nombres propuestos para la comision previa: el Marqués de Comillas (Madrid), 
Finalmente el Estatuto o Bases de la Unión electoral católica española, iba precedido de un comentario sobre la constitución en el Movimiento católico italiano de la «Unión Electoral católica» (abril 1907 en Florencia), y seguido de un comentario final sobre la forma de implantar en España dicha unión electoral.

Aun respetando una cierta autonomia para las "Asociaciones incorporadas" que "quedarán en libertad para la elección de direcciones particulares y medios correspondientes acomodados a los intereses y exigencias de cada localidad», los «medios» previstos (una secretaria central permanente, una estadistica del movimiento electoral católico, la publicación de un boletin de instrucciones e informaciones) apuntaban claramente hacia la constitución de algo nuevo, que sólo había llegado a constituirse en algunas localidades (las ligas católicas). Se trataba sin duda del proyecto más dificil y ambicioso; el más constantemente impulsado, sin éxito, por la Santa Sede desde los primeros Congresos Católicos, en especial desde el de Burgos. Era la verdadera cuestión pendiente de la A.C. española, pues las otras dos Uniones estaban ya en vias de implantación y consolidación.

Se proponian los nombres de personas representativas de los distintos partidos católicos: Mella por los carlistas, Senante por los integristas, y uno por los alfonsinos católicos entre el presidente del Comité de defensa social de Madrid, o Rafael Marin Lázaro, o Francisco G. Rojas, o Rafael $R$. de Cepeda. Se insistia en Madrid como sede remitiéndose a los argumentos planteados en la presentación de la Unión Popular.

Para estimular dicha unión se recordaban los últimos e insistentes llamamientos a la unidad de parte de la Santa Sede, asi como los ejemplos de colaboración y pluralismo suprapartidista que se estaban dando en la acción social católica (consejos diocesanos, semanas sociales), y en la formación de «ligas católicas" con un objetivo más directamente electoral en Zaragoza, Valencia, Mallorca ".

Junto a las Bases para las tres Uniones, se adjuntaban unas Reglas prácticas sobre la unión católico-electoral, que concretaban los criterios posibilistas que debían guiar el comportamiento de los católicos en los momentos electorales. Insistiendo en el criterio del «mal menor» acon-

Jose M. ${ }^{a}$ de Urquijo (Bilbao), Ramón Albó (Barcelona), Luis Herce o Inocencio Jiménez (Zaragoza).

$"$ Sobre la liga católica de Mallorca vid. la tesis citada de P. Fullana; sobre la de Valencia COMEs IGLESIAS, V., «Movilización católica en una capital republicana: Valencia, 19011910" comunicación al Simposio "La política conservadora en la España Contemporánea (1868-1982)". Madrid, noviembre 1991. 
sejado en la carta "Inter catholicos Hispaniae» se confirmaba la política de amplias coaliciones electorales que en algunos lugares ya se estaba llevando a la práctica. Algunas respuestas se referian concretamente a estas «reglas prácticas".

\section{LAS RESPUESTAS}

La encuesta suscitó en la jerarquía eclesiástica española un distinto grado de respuesta y de interés. Pero en todo caso obligó a la reflexión, al planteamiento de problemas que interesaban hasta ese momento a un minoritario grupo de propagandistas. Por tanto las respuestas nos dan un perfil de la sensibilidad social y politica de los obispos españoles de la época. Entre ellas se distingue bien la respuesta meramente protocolaria y obediente al deseo romano, de la más elaborada y personal, tras la que se revela una experiencia y unos criterios. Por eso más allá del resumen final que elabora el nuncio -sobre 59 obispos, 29 son totalmente favorables, cuatro contrarios a la intervención de Roma, nueve no contestan, y 17 "se pronuncian por una parte y no para otra" - el resultado real de la encuesta viene dado por los informes, más elaborados, de aquellas personas más comprometidas en la acción social católica, que con realismo discriminan entre la viabilidad de la «unión popular» y la «unión económico-social», a partir de lo ya existente, y la imposibilidad de crear la unión politico-electoral.

En relación con el modelo de A.C. que se proponia, la mayoria de las respuestas lo aceptan, siempre que se partiera de las organizaciones preexistentes (varios obispos ponderan el funcionamiento de los "Consejos diocesanos"), y subrayando mucho la autoridad del obispo en cada diócesis. En esta línea, el informe de la provincia eclesiástica de Valladolid, que presentamos, se manifestaba reticente a conceder un protagonismo excesivo a los seglares. La reciente experiencia de desobediencia seglar (periodistas integristas) aconsejaban reforzar la dirección del obispo en detrimento del protagonismo seglar.

Respecto a la Unión Popular y la Unión Económico-social la mayoría de los obispos consideraban factible su implantación, aunque algunos señalaban los conflictos que podian surgir si no se tenia en cuenta la creciente tendencia regionalista. En las respuestas de algunos obispos se advierte cierto recelo anticentralista, mientras que otros se lamentaban 
del auge de esta tendencia y apoyaban un modelo unitario con sede en Madrid, tal como argumentaban las bases propuestas ${ }^{12}$.

Respecto a la Unión político-electoral varios informes expresaban con la misma rotundidad que lo hará el documento colectivo de los obispos castellanos que presentamos, su inviabilidad práctica, por la pervivencia de la división política de los católicos españoles. Entre ellos destaca la opinión del obispo de Orihuela Juan Maura Gelabert: «En materia de unión católico-electoral no hemos adelantado nada. Estamos lo mismo que antes. Por lo demás la linea divisoria entre católicos y no católicos no está todavia trazada en España (...) ¡Si hasta los que se llaman católicos dinásticos son mirados por muchos con recelo y desconfianza y calificados despectivamente de mestizos!". O la del obispo de Jaén, Laguarda, muy favorable a impulsar la unión electoral a partir de la experiencia de las Ligas católicas, pero consciente de la resistencia carlista: «los carlistas, no se resignarán fácilmente a dejar su autonomia como partido politico, ni a sacrificar sus comités, ni menos a apoyar candidatos conservadores o católicos alfonsinos independientes".

El obispo de Barcelona, Casañas, dejaba constancia de un dato nuevo, el catalanismo, como factor hegemónico y aglutinante: «Es bien sabido que el objeto primario del catalanismo en cuanto a elecciones, es sacar todo el número posible de diputados catalanistas, a cuyo fin se subordina todo incluso los sentimientos religiosos en los candidatos a la diputación o el Municipio. Por esto hemos visto candidaturas compuestas de católicos y anticatólicos, con tal que fuesen catalanistas, presentadas por el partido frente a frente de candidaturas de fervientes católicos aprobadas por el Prelado. La Solidaridad catalanista domina en esta tierra, y a no ser que cambie de táctica el partido, no será fácil o tal vez posible contrarrestar sus esfuerzos" ${ }^{13}$.

Al margen de las respuestas episcopales hay que tener en cuenta las de los religiosos y seglares más comprometidos con la acción social y católica, los P. Palau y Vicent, también los provinciales jesuitas de Aragón y Toledo, el Marqués de Comillas, y Rafael Rodríguez de Cepeda. Un denominador común preside estas respuestas: la defensa y justificación de

\footnotetext{
12 Los recelos anticentralistas aparecen claramente en las respuestas de los obispos de Vich, Barcelona y Tarragona. Todos ellos advertian de la conveniencia de fundar la Unión Popular a partir de la Acción Social Popular fundada en Barcelona por el P. Palau. En cambio el obispo de Jaén, Laguarda, futuro obispo de Barcelona, expresaba una opinión abiertamente anticatalanista. La nueva Unión Popular, con sede en Madrid, debia sustituir a la Acción Social Popular.

${ }^{13}$ Respuesta de Casañas de 19-IX, en ASV, N. Madrid, 690, 2, ff. 82-83.
} 
las obras ya fundadas, y, por tanto, una cierta actitud de resistencia a la implantación de las nuevas bases.

El informe de Rafael Rodriguez de Cepeda, catedrático de Derecho Natural en la Universidad de Valencia y líder del Movimiento católico en esa ciudad, es muy representativo de los criterios mayoritariamente expresados en la encuesta, que fueron los que finalmente inspiraron las directrices vaticanas: «mi parecer por tanto sería que se comenzara a fundar la "Unión Popular" según los estatutos indicados, ya que en este terreno la lucha y la división entre los católicos es mucho menor, y cuando esta unión esté organizada, entonces se podria proceder a la económico-social, dejando por el momento aparte la electoral, cuando se trata de una organización general y central, limitando la unión sobre este terreno a la fundación de ligas, de alianza electorales aisladas en las principales ciudades" 14 .

El resultado de la encuesta era claro:

- Tanto la unión popular como la económico-social eran perfectamente viables y deseables. Todos se mostraban dispuestos a potenciarla, siempre a partir de las organizaciones y obras preexistentes.

- La unión electoral, forma atenuada de partido católico, era inviable por la persistencia de las viejas rivalidades politicas entre carlistas, integristas y alfonsinos. En esta conclusión se muestran de acuerdo la mayoria de los encuestados, especialmente los más comprometidos con la acción social católica, que cotidianamente experimentaban dificultades.

El peso de esta opinión es reconocido por el nuncio (Vico), y el Secretario de Estado (Merry) que aconsejan el abandono de ese objetivo, siempre pendiente, y la potenciación de la acción católica y social, reforzando la autoridad del primado (Normas de Aguirre). Las primeras directrices concretas del cardenal Aguirre para la Acción católica y social (enero 1910) son la consecuencia directa y final de la encuesta de 1908.

Se puede decir que a la altura de 1910 pervivian las dificultades de 1900 para la constitución de un frente católico unido. Algunas iniciativas episcopales y algunas diócesis estaban logrando sin embargo un grado mayor de cohesión. En la diócesis de Barcelona se habia creado una Aso-

${ }^{14}$ La respuesta de Cepeda, el 5-1X-1908, enviada por el arzobispo de Valencia junto con su respuesta, en ASV, N. Madrid, 690 (2), ff. 52-53. 
ciación de eclesiásticos para el Apostolado Popular, y se celebró una primera Asamblea diocesana en 1911. En Madrid se celebra también la primera Asamblea diocesana de la A.C. en 1912. En Valencia Rafael Rodriguez de Cepeda y el obispo Guisasola impulsaban esta línea de acción. Paralelamente, Asambleas Regionales (desde 1904) y Semanas Sociales (desde 1906), impulsaban la coordinación diocesana, regional y nacional de la acción social católica.

\section{LA RESPUESTA DE LOS OBISPOS CASTELLANOS ${ }^{15}$}

La respuesta colectiva de la provincia eclesiástica de Valladolid, (obispos de Salamanca, Ciudad Rodrigo, Zamora, Astorga, Segovia y Ávila) elaborada en la reunión tenida en Salamanca en septiembre de 1908, es una de las más interesantes entre las remitidas al nuncio, tanto por la riqueza de argumentos y matices que plantea, como por su coincidencia con la opinión dominante en el conjunto de la encuesta. Opinión que es la que inspira tanto el resumen general del nuncio como las directrices que finalmente da Roma para la Acción Católica en España.

Las «observaciones» al folleto titulado "Normas y bases para la acción católica española" que el colectivo de obispos castellanos había elaborado en la reunión de Salamanca van precedidas de una carta del arzobispo de Valladolid, Jose Maria Cos, en la que resume los principales acuerdos tomados en respuesta a las circulares del nuncio. Indicando expresamente su sometimiento obediente a las directrices vaticanas, $y$, especialmente, su aceptación como norma de conducta de las «cuatro reglas insertas a continuación de la Circular de V.E. de 30 de junio bajo el epígrafe "Algunas reglas prácticas sobre Unión Católica Electoral». En cuanto a la propuesta de constitución de la agremiación sacerdotal nacional (o montepio sacerdotal nacional), los obispos advertian sobre las posibles resistencias que algunos montepíos diocesanos preexistentes podian poner a una asociación de carácter nacional.

15 Informe firmado en Salamanca el 17-IX-1908, mecanografiado, remitido por el arzob. de Valladolid, el 10-X, con el resumen de acuerdos, ASV, N. Madrid, 690, 2, ff. 38-45. El resumen del nuncio señala la coincidencia de criterios con el de Zaragoza, pero este informe fue remitido con posterioridad, el 31-X; y en efecto, sigue literalmente párrafos del informe de Valladolid.

Constituian la provincia eclesiástica el arzobispo de Valladolid, J. M. Cos, y los obispos de Astorga, Julián Diego y Garcia Alcolea; Ávila, Joaquín Beltrán Asensio; Ciudad Rodrigo, Ramón Barberá Boada; Salamanca, Francisco J. Valdés Noriega; Segovia, Julián Miranda Bestuer, y Zamora, Luis Ortiz Gutiérrez. 
Pero lo más interesante era la reflexión global que los obispos hacian sobre la propuesta de organización de la acción católica española según el modelo de la triple «unión» italiana.

En cuanto a la "organización de la acción católica" las pocas observaciones concretas trataban de reforzar la autoridad y autonomia de cada obispo en su diócesis como el máximo responsable de la A.C., y frente a cualquier injerencia seglar. Estaban aún recientes los conflictos que algunos obispos habian mantenido con periodistas integristas, con amenazas de excomunión incluida, a propósito de la correcta interpretación de directrices vaticanas.

En relación con la Unión Popular, el documento contiene una crítica directa y radical de la táctica violenta empleada tradicionalmente por el catolicismo español, a diferencia del alemán e italiano: es decir, la lucha armada del carlismo. En su lugar, y a semejanza de los modelos citados, los obispos compartian el criterio vaticano de organizar y reforzar la acción cívica, social y religiosa. En esa táctica estaban todos, cada vez más, teóricamente de acuerdo. Pero los obispos advertian sobre el obstáculo que suponia la pervivencia en España de los viejos métodos.

Además se reconocía como obstáculo la existencia de rivalidades regionales crecientes. Como ya hemos señalado, varias de las respuestas, especialmente la de Palau y los obispos catalanes, manifestaban su recelo a constituir en Madrid una nueva organización, Unión Popular, cuando ya funcionaba en Barcelona, para fines análogos y con la expresa aprobación del Vaticano, la Acción Social Popular.

La alusión a la Unión económico-social, muy breve, compartia esencialmente la propuesta vaticana, que en este terreno concreto, los obispos confiaban se podria llevar a cabo sobre la base de un movimiento organizativo ya pujante, especialmente a partir del Congreso de Burgos, y de las recientes Asambleas regionales de corporaciones católico-obreras.

La referencia más larga y, con mucho, la más interesante, era la que se dedicaba a la cuestión más delicada y polémica de la propuesta vaticana, la «Unión Electoral Católica».

En primer lugar se hacía una interesante valoración del apoyo católico, militante y electoral, con que contaba cada uno de los partidos politicos de la Restauración. En esa presentación, el partido carlista y el integrista quedaban claramente descalificados. El primero, por la pervivencia de la cuestión dinástica como cuestión fundamental y por "sus tradicionales aspiraciones a la guerra civil». El partido integrista era además considerado como un partido en franca decadencia: "un factor poco influyente en la vida política española». En cambio, se subrayaba la importan- 
cia cuantitativa del número de católicos «neutros", sin partido al que votar, "una masa no pequeña de católicos que, no siendo partidarios de un cambio de dinastia, no han querido tampoco sumarse a los partidos turnantes en el gobierno durante el periodo de la Restauración».

En cuanto al partido conservador, en el que distinguía una "derecha constituida por católicos», y una «izquierda constituida por doctrinarios de la escuela conovista", los obispos valoraban positivamente el progresivo liderazgo de Maura con un programa reformista, y lo consideraban, de acuerdo con la tesis accidentalista, como "lo menos malo posible» desde la perspectiva católica.

También se hacia una referencia a los partidos "anticlericales», cla. ramente opuestos a los intereses católicos: el partido liberal cuyo canalejista critican, y los partidos republicanos y socialista que "sostiene un programa bastante concreto".

A partir de este panorama político los obispos se planteaban abiertamente la posibilidad de constituir un partido católico. Tras lamentar y descalificar una vez más la opción carlista por su rechazo intrínseco del principio accidentalista, los obispos consideraban en términos muy realistas y precisos, que revelan un buen conocimiento de la realidad política, los obstáculos que se oponian a la constitución de la "Unión electoral católica». Lo lógico seria integrar en ese bloque representantes de todos los partidos que, según el análisis precedente, tenían alguna base católica. Es decir, desde los carlistas hasta los conservadores mauristas. Pero reconocian con realismo que tal integración era imposible por exclusiones recíprocas. El mismo problema se plantearia a la hora de elegir la dirección de esa unión electoral. No había nadie con autoridad y capacidad de convocatoria suficiente.

La respuesta era pues claramente pesimista. Ante la imposibilidad práctica de constituir la "unión electoral católica", en el plano nacional, sólo quedaba seguir poniendo en práctica en el plano diocesano las reglas contenidas en "Inter Catholicos Hispaniae" (consagración de la tesis accidentalista del “mal menor», 1906), e impulsar las experiencias de colaboración que se estaban dando en algunas ciudades ("Ligas católicas" en Sevilla, Valencia) a la espera de tiempos más propicios.

Lo más significativo de la respuesta de los obispos castellanos no era el reconocimiento pesimista de la inviabilidad de la Unión electoral, sino la critica y descalificación de los obstáculos. Especialmente su referencia explicita a los intocables partidos carlista e integrista. 


\section{DOCUMENTO}

Carta del arzobispo de Valladolid, Jose María Cos, al nuncio, 10-X-1908. Le adjunta informe elaborado por los obispos de la provincia Eclesiástica *.

\section{EXCMO. SEÑOR:}

En la Conferencia Episcopal celebrada en la ciudad de Salamanca los dias 15, 16 y 17 de septiembre próximo pasado se leyó la Circular de V.E. fecha 18 de marzo último en que se recomienda a los Obispos que traten en las Conferencias Episcopales de los medios más conducentes para llegar a unir a los católicos en la "ACCIÓN CATÓLICA" e indica la conveniencia de comunicar al Excmo. Sr. Cardenal Primado el resultado de las deliberaciones episcopales. A continuación se leyó también la Circular de V.E. fecha 30 de junio del corriente año y de los tres documentos que acompañan a esta segunda Circular a saber: "ALGUNAS REGLAS PRÁCTICAS SOBRE LA UNIÓN CATÓLICA ELECTORAL" un folleto titulado «NORMAS Y BASES PARA LA ACCIÓN CATÓLICA ESPAÑOLA» y una hoja dirigida al clero español y titulada «AGREMIACIÓN SACERDOTAL NACIONAL". Después de una amplia discusión en que cada uno de los Rdos. Prelados emitió su dictamen, se adoptaron por unanimidad los acuerdos siguientes:

1. Manifestar respetuosamente a V.E. que los Obispos de la Provincia Eclesiástica Vallisoletana están dispuestos a cumplir exactamente cuando la Santa Sede les ordene con el fin de fomentar la Acción Católica.

2. Aceptar como norma de conducta las cuatro reglas insertas a continuación de la Circular de V.E. de 30 de junio bajo el epigrafe «ALGUNAS REGLAS PRÁCTICAS SOBRE UNIÓN CATOLICA ELECTORAL" ", comprometiéndose cada uno de los presentes a darlas a conocer cuando el caso lo requiera y en la forma que estime más oportuna.

3. Presentar a V.E. las adjuntas observaciones al folleto titulado "NORMAS Y BASES PARA LA ACCIÓN CATÓLICA ESPAÑOLA» y enviar también un duplicado de las mismas a V.E. por si estima conveniente remitirlo al Excmo. Cardenal Primado.

4. Hacer presente a V.E. que la agremiación sacerdotal diocesana es muy conveniente y que en varias de las Diócesis de la Provincia Eclesiástica existen Montepíos sacerdotales y se trabaja para crearlos en otras; pero que la agremiación sacerdotal nacional tropezará con algu-

* ASV, Nunciatura. MADRID 690, 2, ff. 38-45.

${ }^{16}$ El documento "Algunas Reglas prácticas sobre unión católica electoral", cuyas directrices acatan los obispos, reproduce las directrices posibilistas contenidas en «Inter Catholicos Hispaniae". 
nos inconvenientes graves, entre otros el de que probablemente se resistirán a ella los Montepios ya establecidos.

Lo que tengo el honor de comunicar a V.E. en nombre de todos los Prelados de esta Provincia Eclesiástica.

Dios guarde a V.E. muchos años.

Valladolid 10 de octubre de 1908.

Excmo. Nuncio Apostólico de S.S. en España.

Fdo.: José M. ${ }^{a}$, Arzobispo de Valladolid.

\section{DISCUSIÓN DE LAS NORMAS Y BASES PARA LA ACCIÓN CATÓLICA ESPAÑOLA}

La conveniencia y aủn la necesidad de organizar las fuerzas católicas en España es tan evidente que no necesita demostración. La misión de la Iglesia es del orden sobrenatural y a él se endereza; pero, como ha de ejercerse entre hombres, necesita de medios humanos que le sirvan de instrumentos para alcanzar el altisimo fin de la salvación de las almas. Asi como en el orden natural el alma tiene facultades de categoria superior a las de los sentidos; pero tiene necesidad de éstos para su funcionamiento, así la Iglesia fundada por Cristo para elevar las almas a un orden superior al que les corresponde por su naturaleza ha de usar de medios naturales que le sirvan para influir en ellas. $Y$ es de notar, que si bien su Divino Fundador dotó a la Iglesia de una organización adecuada a la misión dogmática que le confió, ha dejado a la iniciativa de los Pastores de la misma Iglesia organizar en una u otra forma a los fieles para todos aquellos fines que pertenecen al número de las múltiples y variadas aplicaciones que es necesario hacer de los principios dogmáticos a las diversas circunstancias en que la vida humana se desarrolla. Estas instituciones secundarias a pesar de no ser esenciales a la vida de la Iglesia, son de grandisima importancia para ella y deben organizarse siempre que sea posible.

De aqui se deducen las dos condiciones fundamentales que deben informar las instituciones dichas: la primera es que sus fines estén subordinados a las doctrinas y enseñanzas de la Iglesia y la segunda que su organismo se apoye en el organismo de la misma Iglesia y sea inspirado y vivificado por éste.

El principio fundamental que han de tener presente los católicos al intentar organizarse para la defensa de los intereses religiosos de su pais es que no sólo tiene la Iglesia autoridad en materias de fe y costumbres en las que es infalible, sino en todas las demás que de cerca o de lejos interesan a la misión altísima que Cristo le ha confiado, pues si bien no tiene infalibilidad más que en las primeras, goza en todas de asistencia especial del Espiritu Santo. Además es justo que, cuando los católicos disienten respecto a puntos discutibles en que cada cual pueda licitamente sustentar opinión distinta se siga la que señalare como más 
conveniente el Obispo respectivo en cada una de las Diócesis y el Romano Pontifice en todo el orbe católico. $Y$ esto aunque pareciese dicha opinión menos acertada que la propia. La razón es porque, siendo en muchos casos necesario aunar las fuerzas de todos en una dirección determinada para evitar que moviéndose en direcciones diversas la acción resulte nula, sólo la lglesia tiene derecho a resolver con la autoridad que recibió de su Divino Fundador cuál es la actitud que conviene adoptar atendidas las circunstancias del momento.

Estas consideraciones movieron a los Obispos reunidos en la Asamblea regional de Palencia ${ }^{17}$ a rogar a nuestro Santisimo Padre Pio $X$ que en fecha reciente habia organizado las fuerzas católicas de Italia, extendiese dicha organización a España, salvas siempre las modificaciones que aconsejaran las circunstancias especiales de la nación española y dejando aparte la organización electoral, que no parecia conveniente abordar por el momento por las razones que más adelante se expondrán.

Los motivos que parecen aconsejar que el fin inmediato y principal de la organización sea la acción social son los siguientes:

1. Porque la cuestión social es la más importante de las que en la actualidad solicitan la atención de los estadistas.

2. Porque es de tal naturaleza que en ella se incluyen las más fundamentales cuestiones del orden religioso-social como son: el origen del poder y sus limitaciones; los deberes de los súbditos; la existencia del derecho de propiedad y los principios a que debe someterse su reglamentación...

$3 .^{\circ}$ Porque es la que más interesa a las muchedumbres, de tal suerte que de su resolución en sentido católico o anticatólico depende, en cuanto se alcanza a la prudencia humana, que los pueblos conserven la fe o la pierdan.

4. ${ }^{\circ}$ Porque en este punto coinciden todos los católicos, aun los que están divididos en distintas banderias politicas ${ }^{18}$.

5. Porque existe ya un principio de organización de las obras sociales que facilita los trabajos que hayan de hacerse en lo sucesivo.

\footnotetext{
17 Asamblea Regional de Corporaciones católicas del Norte celebrada en Palencia, mayo 1906. Crónica de la asamblea publicada en el «Boletin del Consejo Nacional de Corporaciones Católico Obreras".

En la correspondencia del Nuncio con la Secretaria de Estado y en las circulares del nuncio a los obispos, se alude a esta iniciativa de los obispos españoles, lo que no oculta la principal responsabilidad de la Santa Sede y del nuncio en la encuesta sobre la aplicación a España del modelo italiano.

${ }^{18}$ Esta justificación de la prioridad de la acción social como terreno propicio para la unidad de acción, superadora de las fuertes divisiones en la acción politica, y, en ese sentido, preparadora de una posible unión en ese terreno, aparece con frecuencia en los discursos de los propagandistas, Amando Castroviejo, Severino Aznar, etc.
} 


\section{OBSERVACIONES A LAS «NORMAS FUNDAMENTALES A LA ACCIÓN CATOLICA EN ESPAÑA»}

\section{Al artículo 1.}

Si bien es indiferente en principio que los Centros Diocesanos tomen un nombre u otro, convendrá que, una vez elegido todos acepten la misma denominación, pues han de formar parte de un conjunto organizado. Estando ya en muchas Diócesis constituidos Consejos Diocesanos en relación con la Junta General de Acción Católica, pudiera aceptarse dicho nombre.

\section{Al 2. .}

El que los miembros del Centro Diocesano deban ser “necesariamente" los delegados oficiales de las asociaciones católicas más importantes existentes en la Diócesis ofrece algunos inconvenientes: el primero que la mayor parte de las Diócesis tienen muchas asociaciones y por consiguiente resultaria excesivo el número de vocales del Centro con perjuicio de su eficacia, pues la experiencia enseña que las juntas numerosas funcionan mal y con embarazo: el segundo que siendo tan propio del carácter español el amor a la independencia, no seria fácil que los delegados de diversas asociaciones dotadas ellas de vida más o menos próspera trabajen con entusiasmo en constituir una nueva, que, al menos en la apariencia, ha de disminuir algún tanto la autonomia de las mencionadas asociaciones. Acaso fuese más práctico que cada Prelado pudiese constituir libremente el Consejo Diocesano con las personas que juzgase más a propósito y estas fuesen preparando la adhesión de las asociaciones católicas de la Diócesis a dicho Centro. Las asociaciones que se adhiriesen obtendrian por este acto derecho a nombrar un delegado o representante. Esta idea parece indicarse en el articulo $5 .^{\circ}$

\section{Al $3 .^{\circ}$.}

Convendrá que el representante del Obispo tenga la facultad de suspender cualquier acuerdo del Centro Diocesano que no le pareciese conveniente, dando cuenta de dicha suspensión al Prelado el cual resolverá si procede anularlo y en este caso lo comunicará al Centro que tendrá el deber de acatar esta resolución ${ }^{19}$.

\section{Al $6 .{ }^{\circ}$.}

Este articulo es un poco vago y será preciso concretarlo más. Convendrá que la dirección de todos los Centros Diocesanos esté encomendada a una junta central, sea la que ya existe sea otra que la sustituya y que todos los dichos Centros procuren cumplir las órdenes que procedan de dicho centro superior, conservando sin embargo la facultad de exponer las observaciones que juzguen oportunas

19 En todo este apartado se aprecia el reforzamiento de la autoridad y la iniciativa epıscopal sobre cualquier otra instancia, seglar o supradiocesana. 
contra las resoluciones de la junta central ante su propio Diocesano quien hará de ellas el uso que le pareciere ${ }^{20}$.

Respecto al reglamento tipo que se inserta a continuación sólo ocurre observar que para formular el que haya de adoptarse será conveniente consultar varios y procurar que el definitivo tenga la suficiente flexibilidad para acomodarse a las diversas Diócesis sin sufrir alteración sustancial.

"UNIÓN POPULAR CATÓLICA"

La UNIÓN POPULAR O VOLKSVEREIN ha producido excelentes resultados en Alemania y su adaptación a Italia los promete abundantes, mas para intentarla en España es preciso tener presentes algunas circunstancias que no concurren en Alemania ni en Italia. La primera es que la historia de nuestras luchas durante el siglo $x \mid x$ señala en los seglares que se han constituido jefes de agrupación una peligrosa tendencia a emanciparse de la autoridad episcopal y a obrar como si nada tuviese que ver dicha autoridad con las cuestiones politico-religiosas ${ }^{21}$

La razón de esta tendencia es a nuestro parecer que los católicos españoles durante todo el siglo pasado sólo han sabido organizar guerras de religión, considerando la lucha en los campos de batalla como el único o al menos el más adecuado medio para lograr el triunfo de las ideas católicas en las esferas gubernamentales. Este sistema, además del grave daño que encierra confundir con los intereses religiosos otros secundarios y discutibles, lleva como consecuencia natural el mal no pequeño de apartar a los católicos de la dirección de los Obispos.

El proceso por medio del cual se llega a este resultado es muy lógico. Si es necesario que los católicos se organicen en el campo de batalla no pueden ser sus jefes los Obispos cuya misión es de paz, sino que necesitan jefes militares que sepan guiarlos a la victoria. Si la acción militar es la principal el jefe militar es el que con preferencia ha de ser obedecido. Si todos los demás medios son

\footnotetext{
20 Se acepta la coordinación de una Junta Central, pero se salvaguarda siempre la autonomia diocesana. Criterio dominante en todas las respuestas, que lógicamente condicionó el desarrollo de organizaciones nacionales.

${ }^{21}$ Directa alusión a los lideres integristas, Ramón Nocedal al frente, que desde los años 80 del siglo xix han mantenido fuertes polémicas y conflictos con la jerarquia eclesiástica sobre la interpretación correcta de las directrices politicas vaticanas. Siempre rechazando los consejos "posibilistas". La última polémica sobre "el mal menor" a propósito del documento «inter catholicos Hispaniae» estaba vigente. Significaba la descalificación de la intransigencia cintegrista». La historia de esta larga polémica en AndREs GaLlego, J., La politica religiosa en España. 1889-1913, Madrid, edit. Nacional, 1975; Benavioes, D., Cristianismo y Democracia. Madrid, edit. Nacional, 1978, y RoBles, Cristóbal, Insurrección o legalidad, op. cit, y CARCel Orti, V., León XIII y los católicos españoles, op. cit.
} 
inadecuados y secundarios, la acción de los Obispos queda relegada a un segundo término y no se les debe obedecer sino en cuanto lo permita el jefe militar que es el único que tiene en su mano los medios conducentes al triunfo y el único que sabe usar de ellos convenientemente.

Lo contrario sucede en Alemania donde los católicos han otorgado la preferencia a la acción social y religiosa de la que naturalmente los Obispos son el alma y la cabeza.

Otra circunstancia que no debe olvidarse es la de que en Italia la Unión Popular se ha organizado bajo la inmediata inspección y vigilancia del Papa cuya autoridad es incontestada entre los católicos, por lo cual no ha sido dificultoso obtener el asentimiento general de los mismos. En España será mucho más dificil conseguir ese asentimiento.

Por estas razones es menester que si se organiza la Unión Popular Española lo sea bajo una inspección muy inmediata del Episcopado. Para esto será preciso que formen parte del Consejo Directivo alguno o algunos representantes de los Prelados que puedan asistir a las sesiones con voz y voto y consultar los casos ciudosos que ocurrir pudieran, con el Prelado de la Diócesis en la cual resida el Centro o Consejo Directivo de que se ha hecho referencia.

Respecto al «ESTATUTO O BASES DE LA UNIÓN POPULAR ENTRE LOS CATÓLICOS DE ESPAÑA" que se inserta nada nos ocurre que observar. La utilidad y eficacia de las bases dependerá mucho de la forma en que se desarrollen.

A continuación se hacen cálculos acerca del éxito probable de la Unión Popular y de los recursos con que podrá contar desde el momento de su fundación. Dichos cálculos, aunque a primera vista parecen excesivamente modestos, tememos que pequen de optimistas por la dificultad de vencer en España los recelos y desconfianzas que inspira el dar dinero que ha de emplearse en fines aún no bien conocidos. Por otra parte es preciso tener en cuenta la antipatia de algunas regiones con otras y de muchas provincias hacia la capital. Seguramente habria catalán o bilbaíno que daria sin dificultad miles de duros para Barcelona - Bilbao, pero que se negará a dar un puñado de pesetas para obras cuya dirección esté en Madrid ${ }^{22}$.

\section{"UNIÓN ECONÓMICA SOCIAL CATÓLICA ESPAÑOLA"}

La estimamos muy conveniente y creemos que prestará muy eficaces servicios a los intereses católicos de España. Debe establecerse sin precipitaciones y con

\footnotetext{
"Se hace mención en general a posibles rivalidades regionales, a un recelo bastante extendido contra el centralismo madrileño. Sin aludir concretamente a la resistencia de "Acción Social Popular» y del P. Palau a la constitución de otra "Unión Popular" con fines propagandisticos análogos en Madrid.
} 
toda la prudencia necesaria para que no ocurra un fracaso ruidoso que causaría daño tal vez irreparable a las instituciones sociales ya existentes e impediria la formación de otras de la misma índole.

\section{"UNIÓN ELECTORAL CATÓLICA»}

Cuando en la Asamblea Regional de las Corporaciones Católico-Obreras del Norte de España se trató entre los obispos que a ella asistieron y un corto número de los socios más calificados de la misma Asamblea sobre la conveniencia de adaptar a España el triple Estatuto aprobado por Nuestro Santisimo Padre para la nación italiana, se creyó peligroso intentar la Unión Electoral estimando que en nuestra patria cuanto podia hacerse en tan delicada materia estaba ya hecho por medio de la carta «INTER CATHOLICOS HISPANIAE» cuya aplicación seria suficiente luz para los católicos en las contiendas electorales.

Han transcurrido desde aquella fecha algo más de dos años; pero no creemos que las circunstancias hayan variado hasta el punto de que sea hoy fácil y hacedero lo que entonces se creyó peligroso.

La situación y tendencias de los partidos politicos puede señalarse en la actualidad de la manera siguiente:

1. Un partido "carlista" aspirando a ser el exclusivo representante de los intereses católicos de la nación la cual exclusiva es para él mismo de importancia vital, pues adquiere su principal fuerza del sentimiento religioso que vive en el corazón del pueblo español; pero que lleva como enorme contrapeso a sus afirmaciones católicas sus tradicionales aspiraciones a la guerra civil y la pretensión de que sea indispensable para el triunfo del catolicismo la entronización de una dinastia cuya posibilidad no se vislumbra por ahora.

2. Una disgregación del partido anterior que ha tomado el nombre de partido «integrista» el cual, para justificar su separación del carlismo, se ha esforzado en extremar el carácter religioso del partido. Esta agrupación constituyó durante algún tiempo una fuerza importante, no tanto por el número de sus adeptos siempre menor que el de los carlistas, sino mas bien por el valor de las personas que iban a su cabeza. Hoy después de haber sufrido grandes desprendimientos, ha decaido visiblemente y es un factor poco influyente en la politica española ${ }^{23}$.

${ }^{23}$ En efecto a la altura de 1908 el partido integrista estaba en franca decadencia especialmente después de que la postura posibilista vaticana del "mal menor" hubiera sido finalmente defendida por los jesuitas desde la revista Razón y Fe. La muerte de Ramón Nocedal es otro duro golpe para el integrismo. Sin embargo la mentalidad integrista seguiría 
3. El espacio que separa los carlistas de los partidos gobernantes está ocupado por una masa no pequeña de católicos que, no siendo partidarios de un cambio de dinastia, no han querido tampoco sumarse a los partidos turnantes en el gobierno durante el periodo de la restauración. Este grupo, probablemente más numeroso que el partido carlista e indudablemente mas numeroso que el integrista influye sin embargo muy poco en la politica por carecer de jefe y de organización. Además, como los que 10 componen no han encontrado partido de su gusto para intervenir en los negocios públicos, viven retraidos de toda acción politica y dedicados a trabajar más o menos en obras benéficas y sociales. A los que componen este grupo se les suele conocer con el nombre de “neutros" y la mayoria simpatiza hoy con Maura ${ }^{24}$.

4. El partido "conservador» está formado por dos fracciones distintas. La derecha constituida por católicos que ingresaron en el partido por no encontrar otro mejor dentro de la legalidad, pero que sobre los deberes del partido ponen los de hijos fieles de la Iglesia y la izquierda constituida por doctrinarios de la escuela canovista, que admiten el principio liberal de la beligerancia del error; pero desean vivir en buenas relaciones con la Iglesia y no herir los sentimientos religiosos de la nación. Ambas fracciones unidas por el gran prestigio que ejerce Maura sobre ellas forman el partido que ha venido a ocupar el hueco del antiguo partido canovista y en los momentos presentes parece contestar a las evoluciones del partido liberal hacia las izquierdas, evolucionando hacia la derecha y levantando una bandera de reformas sociales y administrativas que es simpática a muchos. El partido conservador es en las circunstancias presentes por que atraviesa la politica española el único no hostil a la Iglesia que está en posibilidad de gobernar. Es por lo tanto «lo menos malo posible» ${ }^{25}$.

pesando e influyendo decisivamente en el catolicismo español en años siguientes, más allá de la desaparición del partido, a través de «El Siglo Futuro». Sobre los origenes del integrismo, vid. Urigüen, B., Origenes y evolución de la derecha española. El neocatolicismo, CSIC, sobre el integrismo en la Restauración, CAMPOMAR, Marta, La cuestión religiosa en la Restauración. Santander 1984, y El integrismo ultramontano y sus efectos en la ideologia y la literatura de la Restauración, comunicación en el simposio "La política conservadora en la España contemporánea», UNED, noviembre 1991; BONET I BALTÁ, J., y MARTi, C., L'integrisme a Catalunya. Les grans polemiques. 1881-88, ed. Vicens Vives, 1990.

${ }^{24}$ Frente a la visión estereotipada que se repite en la historiografia, los obispos ponderan la existencia de una mayoria católica "neutra", ideológicamente antiliberal, pero no adscrita políticamente ni al carlismo ni al conservadurismo, próxima potencialmente al "maurismo".

${ }^{25}$ Sobre el maurismo y la presencia de católicos en esa opción, vid., TUSELL, J., y AVILÉs, Juan, La derecha española contemporánea. Sus origenes, el maurismo, Madrid 1986. RoBLES, C., «Frente a la supremacia del Estado. La Santa Sede y los católicos en la crisis de la Restauración. 1898-1910", Antologia Annua 36 (1989). Comunicaciones sobre "ligas católicas" al coloquio de la UNED sobre "La politica conservadora en la España de la Restauración”. 
5. El partido "liberal» disgregado en varios grupos y grupitos que constituyen las mesnadas con que cada uno de los conspicuos del partido lucha por la jefatura, ha abandonado los limites de relativa prudencia en que Sagasta lo tenía contenido y marcha desatentado en busca de banderas y programas que le atraigan del revuelto campo de la extrema izquierda las fuerzas de que carece. De aqui que pretenda traducir al español la inicua persecución francesa y renovar las persecuciones del progresismo histórico ${ }^{26}$.

6. Los abigarrados grupos que forman la masa caótica que hemos convenido en llamar "extrema izquierda" ofrecen multitud de matices entre los que apenas se destaca algo el partido "socialista" que sostiene un programa bastante concreto. Todas estas banderias solamente se aunan para combatir con odio sectario a cuanto tiene el nombre de católico y prestan gustosas su apoyo a cualquier partido que lleve a efecto el plan desarrollado en Francia: expulsión de las Ordenes Religiosas; enseñanza atea; despojo de la Iglesia hasta reducirla a la miseria; prohibición de todo acto exterior del culto ${ }^{27}$.

La presente situación parecia aconsejar que el partido carlista, abandonando, al menos por ahora, proyecto de guerras imposibles y restauraciones dinásticas irrealizables, formase rápidamente dentro de la legalidad un partido católico que, engrosado con todos los demás elementos sinceramente católicos, hoy dispersos, pudiese tener la esperanza de gobernar y en todo caso ofreciese al Rey y al partido conservador una fuerza de opinión considerable que atrajese a si a dicho partido o al menos una parte muy importante de él. Mas no hay que pensar en que estos bellos ideales se realicen. Las preocupaciones por tantos años mantenidas no pueden borrarse en un instante y por mucho tiempo continuaremos pagando tributo al error de anteponer la forma de gobierno que es lo accidental a los principios que deben informar a los gobernantes, que es lo principal ${ }^{28}$.

Descartando pues esta solución, surge la primera duda. ¿Qué agrupaciones han de formar la Unión Electoral Católica? ¿Ha de extenderse ésta hasta la derecha del partido conservador o sólo han de entrar en ella carlistas, integristas y los neutros que quieran sumarse a ellos? ¿La Union ha de trabajar en inteligencia con el partido conservador o ha de ser enemiga de éste? Todas las soluciones

\footnotetext{
${ }^{26}$ Alusión a la política de los liberales sobre las congregaciones religiosas, desde 1900 y sobre todo bajo el liderazgo de Canalejas, como un factor aglutinante y una bandera oportunista con que renovar el programa. Tesis sustancialmente recogida por buena parte de la historiografía.

${ }^{27}$ Alusión genérica al nuevo republicanismo populista de Lerroux en Barcelona o Blasco Ibañez en Valencia. Sobre el lerrouxismo y su faceta anticlerical, vid. libros clásicos de Connelly Ullman, Romero Maura, y el reciente de Álvarez Junco, J., Lerroux, el emperador del Paralelo. Sobre el blasquismo, Relg, Ramiro, Blasquistas y clericales. Valencia 1986.

${ }^{28}$ Descalificación del carlismo por la cuestión dinástica, y elogio del posibilismo. Eje de la posición defendida en todo el documento.
} 
están erizadas de dificultades. Si se quiere extender la Unión hasta el partido conservador se tropezará con la oposición del carlista, que como cuestión vital para él, sostiene su exclusiva en la politica católica y a lo mas que está dispuesto es a abrir las puertas de la casa paterna a los integristas que por ella salieron y entre tanto a admitir alianza con ellos. Tampoco verá con agrado la Unión el partido conservador cuya disciplina sufriria indefectiblemente quebranto notable. Si se eliminan de la Unión a todos los elementos procedentes del partido conservador, se caerá en el inconveniente de convertir la Unión en agrupación antidinástica, porque es natural que en la reunión de varios grupos al cabo prepondere el más fuerte $y$, como ni el partido integrista por su menor importancia, ni el neutro por no estar organizado pueden competir con el partido carlista, la Unión resultará al fin carlista. Por otra parte dirigida la Unión Electoral Católica a disputar puestos al partido conservador, se corre el riesgo de debilitar éste sin ventaja alguna pues la Unión no podrá constituir partido de gobierno que le sustituya y vendrá a favorecer indirectamente a los partidos liberales ${ }^{29}$.

La segunda cuestión dificil de resolver que se presenta es la siguiente: ¿Quién congrega y acaudilla las huestes de la Unión Electoral Católica? ¿Los Obispos? No lo creemos prudente en atención a muchas razones que omitimos, porque sería larga su enumeración y por otra parte son manifiestas. No pudiendo los Obispos dirigir la Unión las añejas discordias que dividen a los católicos hacen temer que la Unión Electoral o no llegue a constituirse al menos de una manera general y estable, o que desaparezca a poco de establecida destruyendo con su fracaso muchas esperanzas y muchos entusiasmos. Por de pronto no se descubre una persona de prestigio suficiente para que todos acaten su autoridad aunque se la refuerce con la aprobación del Episcopado.

En los comentarios que se insertan a continuación del Estatuto para la Unión Electoral Católica se indica el medio de que el Episcopado nombre una especie de regencia para la cual se indican los nombres muy respetables de los Sres. Mella, Senante y Marin Lázaro, González Rojas o Rodriguez Cepeda. Tal vez por exceso de pesimismo creemos que ni aún al Sr. Mella a pesar del gran prestigio que goza entre los suyos obedecerian todos los carlistas. Pero aún en el caso de que los Sres. indicados lograsen establecer la Unión Electoral; ¿Con qué medios contarian para vencer la resistencia de los candidatos que se creyesen postergados? ¿Y si, como es de suponer tratándose de hombres surgiese entre ellos alguna diversidad de criterio; ¿Quién daria la solución definitiva? ${ }^{30}$.

A lo único a que parece poderse llegar por ahora es a que cada Obispo difunda, valiéndose para ello de los medios que estime convenientes, entre sus dio-

29 Interesante valoración de los límites o "techos" de la coalición electoral católica. La cuestión decisiva es la posibilidad de incluir o no a los "conservadores" en esa coalición, y más concretamente la posibilidad real de coexistencia entre carlistas y conservadores.

${ }^{30}$ Además de la extrema división partidista, los obispos señalan como segundo obstáculo fundamental la ausencia de un lider católico con suficiente prestigio y autoridad para aglutinar. 
cesanos la doctrina contenida en la carta INTER CATHOLICOS HISPANIAE y procure evitar las luchas electorales entre católicos, si encuentra medios prudentes para conseguirlo, pues en muchos casos ni aún esto le será posible.

Al menos antes de emprender la crganización de la Unión Electoral Católica, deberá examinarse detenidamente el resultado de las Ligas Católicas y los motivos porque fracasaron algunas de ellas con el fin de estudiar en la historia de lo ocurrido las lecciones que conviene aprovechar en lo porvenir.

Tampoco ha de perderse de vista que la Unión Electoral permanente de una manera más o menos marcada ha de tener enfrente a los partidos politicos existentes, a los cuales tiende necesariamente a absorber, pues siendo el principal medio para obtener la influencia politica en el sistema actual la representación parlamentaria y habiendo de funcionar en cada distrito para la designación de candidatos y manejo de las fuerzas electorales sobre la autoridad de los partidos, la de la Unión Electoral, ésta concluirá por anular a los jefes de dichos partidos. Si no se quisiese destruir a los partidos y se privase a la Unión Electoral de la facultad de resolver en definitiva acerca de la designación de candidatos, dicha Unión careceria de eficacia en absoluto ${ }^{31}$.

Después de haber consignado con toda sinceridad y lealtad las observaciones que se nos han ocurrido concluimos por afirmar que cumpliremos con empeño y entusiasmo cuanto sobre estos puntos o cualquiera otros disponga la Santa Sede o acuerde la mayoria de nuestros Hermanos en el Episcopado, aunque tales disposiciones y acuerdos fuesen contrarios a nuestro propio parecer.

Salamanca, 17 de septiembre de 1908.

${ }^{31}$ Reconocimiento realista de la imposibilidad de crear una Unión Electoral eficaz sobre la base de la disolución de los partidos preexistentes. La formulación de este dilema insoluble fue recogida literalmente por el nuncio en el resumen de la encuesta que elaboró para la Secretaria de Estado. 